\title{
Reactive Oxygen Species-Mediated Tumor Microenvironment Transformation: The Mechanism of Radioresistant Gastric Cancer
}

\author{
Huifeng Gu $\mathbb{D}^{1},{ }^{1}$ Tianhe Huang, ${ }^{2}$ Yicheng Shen, ${ }^{3}$ Yin Liu, ${ }^{1}$ Fuling Zhou $\mathbb{D},{ }^{4}$ Yanxia Jin, ${ }^{4}$ \\ Haseeb Sattar, ${ }^{5}$ and Yongchang Wei ${ }^{1}{ }^{1}$ \\ ${ }^{1}$ Department of Radiation and Medical Oncology, Zhongnan Hospital, Wuhan University, Wuhan, Hubei 430071, China \\ ${ }^{2}$ Department of Clinical Oncology, First Affiliated Hospital, Medical School of Xi'an Jiaotong University, Xi'an, Shanxi 710061, China \\ ${ }^{3}$ School of Medicine, University of Texas Medical Branch, Galveston, TX 77555, USA \\ ${ }^{4}$ Department of Hematology, Zhongnan Hospital, Wuhan University, Wuhan, Hubei 430071, China \\ ${ }^{5}$ Department of Clinical Pharmacy, Wuhan Union Hospital, Affiliated to Tongji Medical College, Huazhong University of Science and \\ Technology, Wuhan, Hubei 430022, China
}

Correspondence should be addressed to Yongchang Wei; weiyongchang@whu.edu.cn

Received 7 October 2017; Revised 30 January 2018; Accepted 26 February 2018; Published 27 March 2018

Academic Editor: Karin Thevissen

Copyright (C) 2018 Huifeng Gu et al. This is an open access article distributed under the Creative Commons Attribution License, which permits unrestricted use, distribution, and reproduction in any medium, provided the original work is properly cited.

Radioresistance is one of the primary causes responsible for therapeutic failure and recurrence of cancer. It is well documented that reactive oxygen species (ROS) contribute to the initiation and development of gastric cancer (GC), and the levels of ROS are significantly increased in patients with GC accompanied with abnormal expressions of multiple inflammatory factors. It is also well documented that ROS can activate cancer cells and inflammatory cells, stimulating the release of a variety of inflammatory cytokines, which subsequently mediates the tumor microenvironment (TME) and promotes cancer stem cell (CSC) maintenance as well as renewal and epithelial-mesenchymal transition (EMT), ultimately resulting in radioresistance and recurrence of GC.

\section{Introduction}

Gastric cancer (GC) is the second most frequently diagnosed cancer and the second leading cause of cancer-related mortality in China [1]. Almost one million new cases are estimated to occur worldwide every year [2]. Radiotherapy (RT) can optimize outcomes in patients with gastric cancer [3]. However, the impact of RT is hindered by a frequent development of resistance to the treatment [4]. Radiotherapy causes tissue damage in two different ways, a direct damaging effect from radiotherapy itself and an indirect effect resulting from the alteration of cellular pathways [5]. Radiotherapy can generate DNA breaks and induce cell apoptosis to indirectly militate against the antitumor treatment by inducing the reactive oxygen species (ROS). ROS are products of an excessive oxidative phosphorylation in mitochondria, as well as products of peroxisome-mediated $\beta$-oxidation of branched and very long-chain fatty acids (VLCFAs) [6], which regulate a variety of important signaling pathways for cell proliferation and survival.

Chronic low-level increased ROS can activate the change of the tumor microenvironment. Radiotherapy typically causes chronic oxidative stress and induces higher levels of ROS. The haemal levels of ROS in gastric cancer patients are obviously increased, along with the abnormal expression of factors such as P38 which modulates the expression of inflammatory factors [7-9]. ROS also directly alter the tumor microenvironment by activating cancer cells and inflammatory cells, which in turn release a variety of inflammatory factors to promote CSC renewal [10], leading to therapeutic resistance [11].

\subsection{Effects of Radiotherapy in Gastric Cancer}

1.1.1. ROS-Associated Radioresistance in Gastric Cancer. The biological effects of radiotherapy are mainly a consequence of DNA damage, such as breaks in the double-strand (ds) 


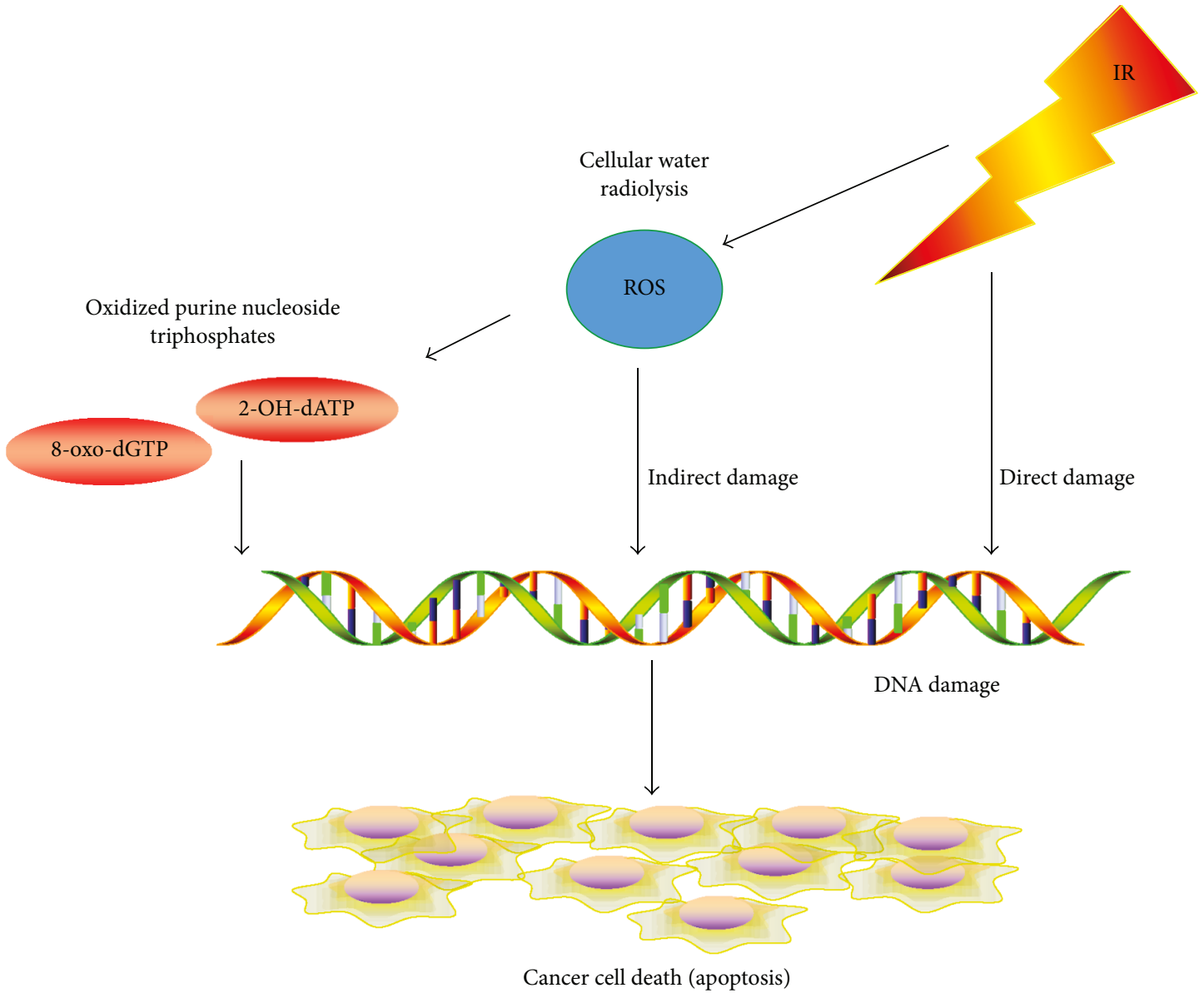

FIGURE 1: Radiotherapy and ROS promote antitumor effects. Radiotherapy irradiation causes cellular death through direct DNA breaks and indirect ROS effects. ROS induces 8-oxo-dGTP and 2-OH-dATP into genomic DNA, which leads to tumor cell apoptosis.

structure. These breaks can be directly caused by interactions between rays and DNA molecules, or indirectly from ROS-related cellular water radiolysis [12] (summarized in Figure 1). High levels of ROS suppress tumor growth through the inhibition of cell proliferation and induction of apoptosis and senescence. Incorporation of oxidized purine nucleoside triphosphates, such as 8 -oxo- $2^{\prime}$-deoxyguanosine triphosphate (8-oxo-dGTP) and 2-hydroxy-2'-deoxyadenosine triphosphate (2-OH-dATP), into genomic DNA plays an important role in apoptosis induced by ROS [13]. In addition, some studies confirm that tumor-infiltrating lymphocyte (TIL) can be attracted by ROS and exert their antitumor effects [14]. However, some cancer cells can survive ROS by activation of DNA repair and the antioxidant system [15]. Consequently, both activation of cellular DNA damage checkpoints and the ability to repair DNA in cells like CSCs contribute to cellular survival after receiving radiotherapy [10].

1.1.2. ROS-Related Alterations in the Tumor Microenvironment after Radiotherapy. Radiotherapy can break the DNA of tumor cells and increase the levels of ROS, leading to damage in tumor cells and changes in the microenvironment. After radiotherapy exposure, normal and tumor tissues show inflammatory responses, including vascular trauma, tissue edema, and hypoxia. Pulmonary fibrosis is one of the most undesired side effects of RT. Studies have confirmed that some RT can cause acute lung injury, and the connective tissue growth factor (CTGF) mediates a chronic inflammatory response resulting in pulmonary fibrosis [16, 17]. Myofibroblast expansion and progressive deposition of the extracellular matrix can be observed in this process. The radiotherapyinduced vascular trauma, tissue self-healing, and immune cell infiltration usually cause an increased demand for oxygen, and the following hypoxic environment activates hypoxiainducible factors (HIFs) [11]. The HIFs, particularly HIF- $1 \alpha$ and HIF- $2 \alpha$, regulate tumor cell proliferation, migration, and angiogenesis by regulating glucose metabolism and ROS production $[18,19]$. The hypoxia also influences the immune system by recruiting immune cells, such as tumor-associated macrophages (TAMs), T-cells, B-cells, and myeloid-derived suppressor cells (MDSCs) [20]. Whether HIFs function positively or negatively in the tumor immune response is not clearly understood. In addition, RT causes tumor cell death and inflammatory infiltration, which induce the release of tumor antigens and trigger antigen-presenting cells [21]. RT also promotes dendritic cell (DC) recruitment and a T-cell immune response through RT-induced IgM targeting of the necrotic tumor cells. The inflammatory environment within tumors can also attract TAMs and T-cells to suppress or promote tumor growth [22]. The microenvironment is deeply 


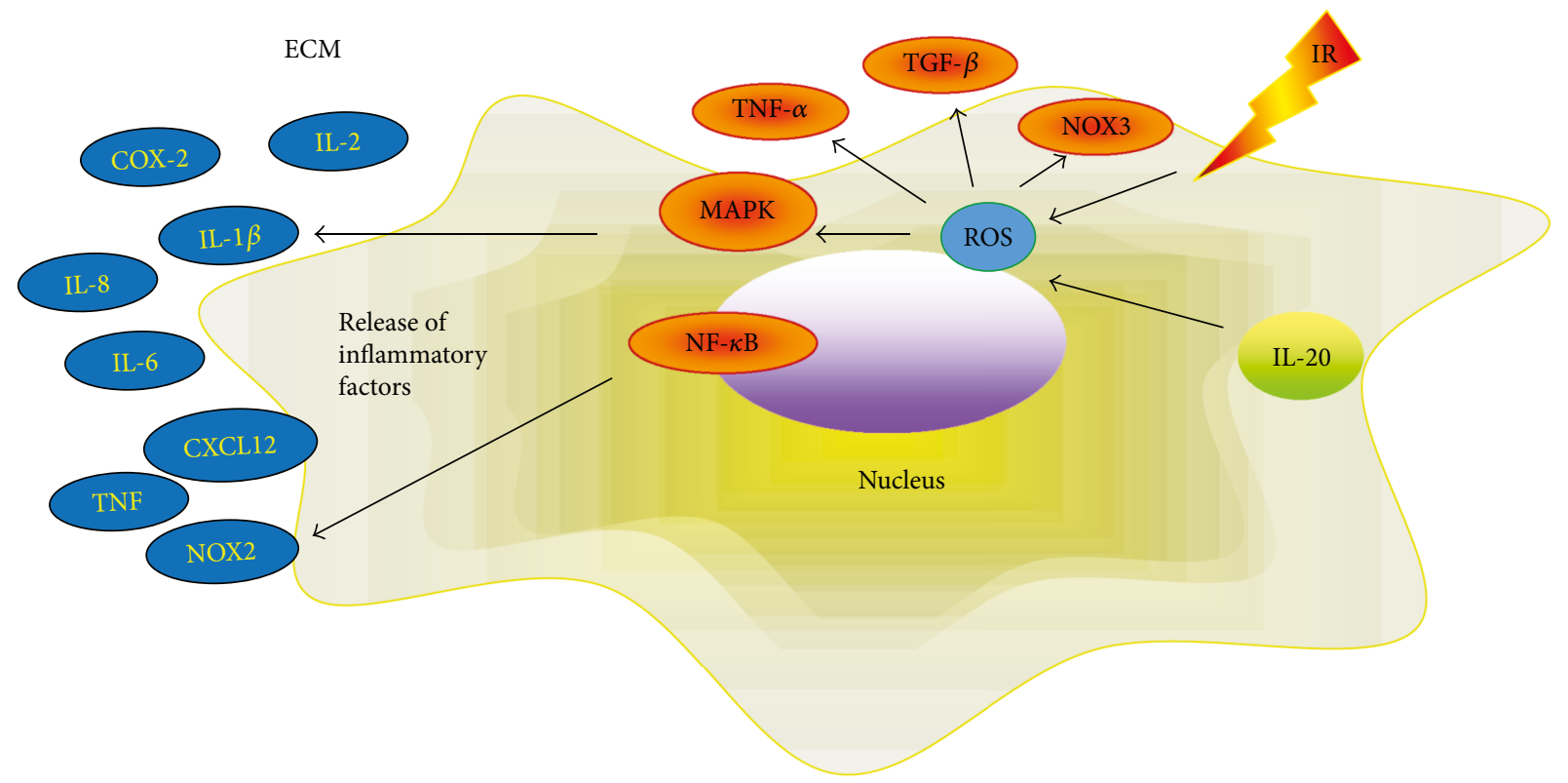

FIGURE 2: ROS mediate TME alterations. ROS can activate TNF- $\alpha$, TGF- $\beta$, MAPK, NOX3, and NF- $\kappa$ B signaling pathways and promote the release of inflammatory factors TNF, NOX2, IL-6, IL-2, IL-8, and CXCL12, leading to tumor microenvironment changes and the development of tumors.

TABLE 1: ROS and TME-relevant signaling.

\begin{tabular}{lccc}
\hline ROS target & Factors & Signaling pathways & Function \\
\hline P38 & TLR2/6 & P38 MAPK, JNK & Translocation of NF- $\kappa$ B to the nucleus \\
NF- $\kappa$ B & IL-1 $\beta$, IL-6, COX-2, IL-2, IL-8, & STAT3, NF- $\kappa$ B p65 & Regulation of tumor proliferation and apoptosis \\
TNF & TNF, NOX2, CXCL12 & [23, 27] \\
TGF- $\beta$ & TNFs & TNF, NF- $\kappa$ B, JNK & Cell survival or death \\
NOX-3 & NADPH & TGF & EMT inducer \\
\hline
\end{tabular}

changed after $\mathrm{RT}$ in response to the effects of ROS, which results in the transformation of TME and contributes to resistant cancer cells.

\subsection{ROS-Mediated Tumor Microenvironment Transformation} in Gastric Cancer Patients. Elevated levels of ROS are closely related to changes in the tumor microenvironment. The interaction between ROS and inflammation is an important pathogenic factor for GC carcinogenesis. Studies have shown that inflammatory mediators, such as cytokines and growth factors, can regulate nitrogen oxides (NOX) to produce ROS [23]. IL-20 stimulates ROS production through the activation of the signal transducer and activator of transcription 3 (STAT3), protein kinase B (AKT)/phospho-c-Jun NH(2)terminal kinase (JNK)/extracellular signal-regulated kinase (ERK) signals [24]. As an effector molecule, ROS attract white blood cells involved in inflammation and tissue damage. Many studies have shown that ROS participate in carcinogenesis by activating inflammatory mediators, thus triggering an inflammatory microenvironment [25]. In Kupffer cells, ROS induce the release of inflammatory mediators by activating P38 to revitalize mitogen-activated protein kinase
(MAPK) and nuclear factor-kappa B (NF- $\kappa \mathrm{B})$ [26]. High levels of ROS can also activate tumor necrosis factor alpha (TNF- $\alpha$ ), protein (p65), and transforming growth factor beta (TGF- $\beta$ ) and downregulate the inhibitor of kappa B alpha $(\mathrm{I} \kappa \mathrm{B} \alpha)$ to mediate the release of inflammatory mediators [23, 27, 28]. In addition, inflammatory cytokines can be released through the signal transducer and activator of transcription 1 (STAT1) signaling pathway, which is activated by ROS [29, 30]. ROS activate NF- $\kappa \mathrm{B}$, TNF- $\alpha$, and STAT3 signaling pathways in inflammatory cells and tumor cells to release TNF, NOX2, IL-6, IL-2, IL-8, and CXCL12 involved in the change of TME $[23,27]$ (summarized in Figure 2 and Table 1). Our former researches and other groups have confirmed that patients with GC are in a status of oxidative stress [32] accompanied by abnormal expression of a variety of inflammatory factors, including IL-1 $\beta$, IL-6, and COX-2. Therefore, ROS may stimulate tumor cells to proliferate and resist apoptosis while promoting the development and progression of GC by impacting the tumor microenvironment.

\subsection{Transformed Tumor Microenvironment Promotes Gastric Cancer Development and Radiotherapy Resistance.}


TABLE 2: CSCs involve in the mechanisms of radioresistance.

\begin{tabular}{lcc}
\hline Mechanism & Signaling pathways & References \\
\hline & PARP & {$[35]$} \\
& ATR-Chk1 & {$[36]$} \\
Protection of & ATR-Cnk1, ATM-Chk2 & {$[37]$} \\
DNA repair & Chk1, Chk2 & {$[38]$} \\
& MTM-ZEB1-Chk1 & {$[39]$} \\
& AKT/cyclin D1/Cdk4 & {$[40]$} \\
& Upregulated DNA repair genes & {$[42,43]$} \\
Protection of & Nrf2 signaling pathway & {$[44-46]$} \\
ROS scavenging & The Prdx family of antioxidant & {$[47,48]$} \\
Protection of & enzymes & \\
TME change & HIF-mediated mechanisms and & {$[14,18,49,50]$} \\
\hline
\end{tabular}

Radioresistant GC cells have stem cell-like features. Several studies have shown that cancer stem cells (CSCs) play an important role in developing resistance and recurrence of cancer. The change of the tumor microenvironment after radiotherapy can activate CSC renewal and epithelialmesenchymal transition (EMT) $[33,34]$. CSCs display an EMT phenotype that is resistant to conventional therapies. Self-renewal of such cells is the main cause for treatment resistance and recurrence of GC (summarized in Table 2). In some human and mouse mammary tumors, ROS levels in CSCs are lower than those found in corresponding nontumorigenic cells (NTCs). Compared to NTCs, CSCs show less DNA damage and are more viable. A highly activated free radical scavenger system contributes to lower levels of ROS in CSCs. Pharmacologic depletion of ROS scavengers in CSCs significantly decreases their ability to form colonies, leading to increased radiosensitivity [51]. These suggest that, similar to stem cells, CSCs in tumors can enhance reactive oxygen defense and reduce ROS levels, which may lead to cancer radiotherapy resistance [15]. Recent reports confirm that ROS are associated with GC stem cell markers CD133, CD166, and CD44 [52-54]; ROS can also regulate EMT-related indicators, such as E-cadherin, N-cadherin, snail, and twist [55].

EMT is crucial not only in regulating tissue development but also in tumor invasion and metastasis [56]. The change of the microenvironment plays an important role in the development of tumors, stem cell transfer, and self-renewal. ROS change the tumor microenvironment by regulating a variety of cell signaling pathways to promote CSC transformation $[57,58]$. ROS also regulate the activity of $\mathrm{NF}-\kappa \mathrm{B}$, which is an important mediator of the release of inflammatory factors by tumor cells $[59,60]$. In breast cancer, head and neck squamous cell carcinoma, gastric cancer, and glioma, IL-6 promotes stem cell self-renewal through the classical IL-6R/ gp130/STAT3 signaling pathway [61] (summarized in Figure 3). An elevated level of IL-6 is related to cancer cell proliferation, angiogenesis, and metastasis via stimulation of MAPK, STAT3, and AKT signaling pathways [62, 63]. IL-6 accelerates EMT through an altered expression of $\mathrm{N}$-cadherin, E-cadherin, twist, snail, and vimentin, which results in cancer metastasis. It is reported that the levels of ROS, IL-6, COX2, and TNF- $\alpha$ are abnormally increased in patients with GC. Therefore, ROS may activate NF- $\kappa$ B to cause GC cells and cancer-associated fibroblast cells (CAFs) to release IL-6, thus mediating tumor metastasis and selfrenewal that will consequently facilitate CSC self-renewal and maintenance. The activation of the cellular DNA damage checkpoint and the ability of DNA repair in CSCs result in their survival of radiotherapy, thus establishing radioresistance in GC cells.

\subsection{Targeting ROS and ROS-Associated Tumor} Microenvironment Signaling Pathways. Recently, multiple medicinal and chemical therapies are investigated to target the factors and signaling pathways associated with ROS-mediated TME alteration, ROS-mediated DNA damage, and apoptosis (summarized in Table 3). Selenium nanoparticles (SeNPs) possess special chemical and physical properties and generate ROS in cells to provide a novel strategy for the rational design and synthesis of chemoradiosensitizing therapeutic materials [65]; SeNPs are also confirmed to affect on TNF and IRF1 to induce ROS-mediated activation of necroptosis [70]. There are also reports demonstrating that an increased level of ROS is a feasible strategy to improve radiotherapy efficacy [64-66]. Most of the drugs like bortezomib, celecoxib, 5-FU, and other compounds are validated to enhance the generation of ROS. Other reports suggest that microRNAs and other materials can repress the factors in ROSmediated TME and enhance radiosensitivity in numerous cancer cells, including GC cells $[72,73]$. Nonetheless, the mechanisms of ROS-mediated TME alteration in GC are not explicitly understood, particularly regarding key genes and proteins that influence the signaling pathways within the TME, inflammatory factors releasing, CSCs, EMT, and ROS scavenging.

\section{Conclusion}

The purpose of radiotherapy is to eliminate tumor cells, but spare normal cells and tissues from radiotherapy damage. However, currently single-course radiotherapy cannot provide sufficiently high-dosage radiotherapy for effective treatment of GC. While ROS can be induced chronically during multiple rounds of radiotherapy, its antitumor effect may be compromised. Within the tumor microenvironment, radiotherapy and several key cytokines can promote ROS production, consequently suppressing the antioxidant system. Patients with GC suffer from chronic oxidative stress and have higher levels of locally induced ROS, which leads to an abnormal expression of cytokines and inflammatory factors. ROS can activate a variety of signal molecules, such as MAPK, NF- $\kappa \mathrm{B}, \mathrm{TNF}-\alpha$, and TGF- $\beta$ that transform the TME by releasing inflammatory factors, including IL- $1 \beta$, IL-6, COX-2, TNF, and NOX2. These inflammatory factors promote the development and progression of GC through cellular proliferation and apoptosis signal pathways. The GC stem cell markers like CD133, CD166, and CD44 are also associated with ROS and EMT markers. ROS can also activate several cell signal pathways to regulate the CSCs. ROS- 


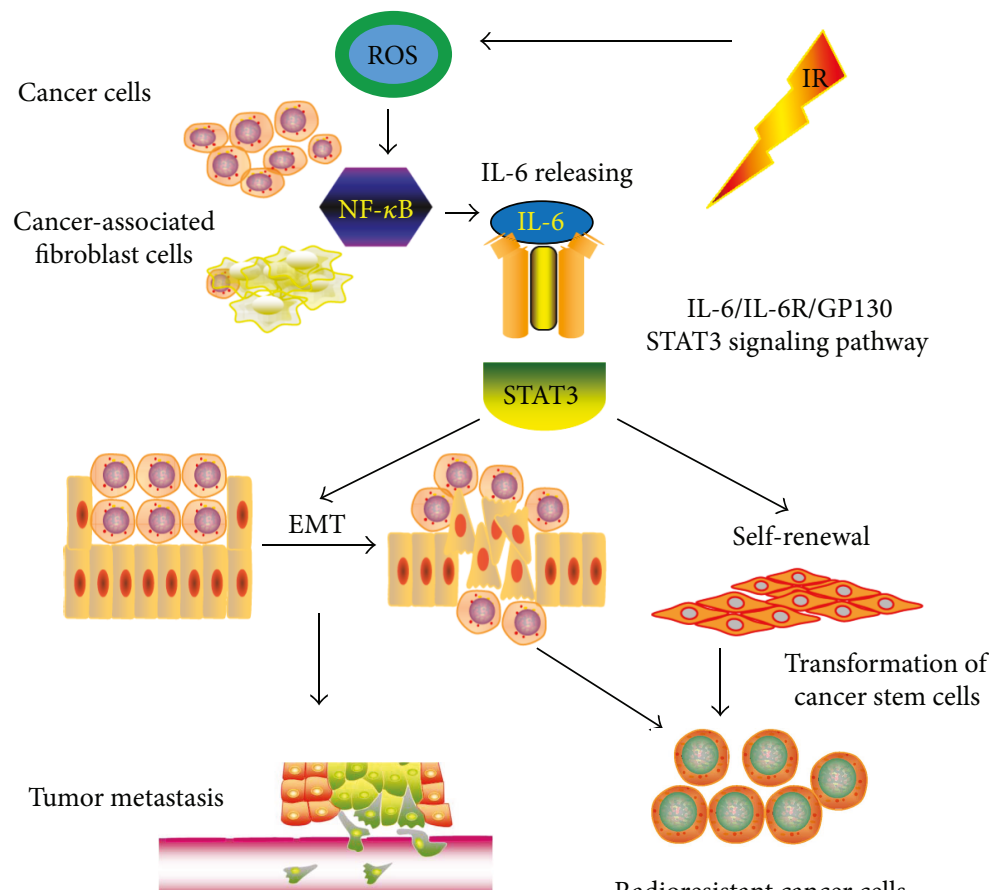

FIGURE 3: The IL-6R/gp130/STAT3 signaling pathway. The IL-6 secreted by tumor cells and CAFs through the ROS-mediated NF- $\kappa$ B signaling pathway can promote tumor metastasis, radioresistance, and CSC self-renewal. IL-6 promotes GC metastasis and CSC self-renewal through the classical IL-6R/gp130/STAT3 signaling pathway.

TABLE 3: Novel therapies targeting the ROS-mediated TME alteration.

\begin{tabular}{|c|c|c|c|c|}
\hline Therapy & Target & Material type & Mechanism & References \\
\hline $\begin{array}{l}\text { BEMER electromagnetic } \\
\text { field therapy }\end{array}$ & ROS & Cancer cell lines & $\begin{array}{c}\text { Enhanced ROS formation and } \\
\text { induced DNA damage }\end{array}$ & {$[64]$} \\
\hline $\begin{array}{l}\text { X-ray responsive selenium } \\
\text { nanoparticles }\end{array}$ & ROS & HeLa and NIH3T3 cells & $\begin{array}{l}\text { ROS overproduction causing the } \\
\text { cell apoptosis }\end{array}$ & {$[65]$} \\
\hline $\begin{array}{l}\text { Diisopropylamine } \\
\text { dichloroacetate }\end{array}$ & ROS & $\begin{array}{c}\text { Human esophageal squamous cell } \\
\text { carcinoma cell lines Eca-109 and TE-13 }\end{array}$ & Modulated mitochondrial oxidation & {$[66]$} \\
\hline Bortezomib, romidepsin & $\mathrm{NF}-\kappa \mathrm{B}$ & Human NSCLC cell lines (A549) & $\begin{array}{l}\text { Increasing ROS and stimulating } \\
\text { the extrinsic pathway of apoptosis }\end{array}$ & {$[67]$} \\
\hline Bortezomib & ROS, Noxa & $\begin{array}{l}\text { Mantle-cell lymphoma cell lines } \\
\text { and patients }\end{array}$ & $\begin{array}{l}\text { Cytotoxic effect through ROS } \\
\text { generation and Noxa induction }\end{array}$ & {$[68]$} \\
\hline Celecoxib, 5-FU & ROS & $\begin{array}{l}\text { Human squamous cell lines (SNU-1041 } \\
\text { and SNU-1076), orthotopic tongue } \\
\text { cancer mouse model }\end{array}$ & $\begin{array}{l}\text { Inhibiting the AKT pathway and } \\
\text { enhancing ROS production }\end{array}$ & {$[69]$} \\
\hline Selenium nanoparticles & TNF, IRF1 & $\begin{array}{l}\text { Human prostate adenocarcinoma cell } \\
\text { line (PC-3) }\end{array}$ & $\begin{array}{l}\text { Causing TNF and IRF1-induced } \\
\text { ROS-mediated necroptosis }\end{array}$ & {$[70]$} \\
\hline miR-139-5p & Multiple genes & $\begin{array}{l}\text { Breast cancer patients, human } \\
\text { breast cancer cell line (MCF7), } \\
\text { xenograft mouse model }\end{array}$ & $\begin{array}{l}\text { Suppression of gene networks of } \\
\text { DNA repair and ROS defense }\end{array}$ & {$[71]$} \\
\hline Ursolic acid & & $\begin{array}{l}\text { BGC-823 human adenocarcinoma } \\
\text { gastric cancer cell line }\end{array}$ & $\begin{array}{c}\text { Enhanced G2/M arrest, increasing } \\
\text { ROS, promoting apoptosis }\end{array}$ & {$[72]$} \\
\hline miR-200c nanoparticles & CSC & $\begin{array}{c}\text { Human gastric adenocarcinoma cell } \\
\text { lines (BGC823, SGC7901, and MKN45) } \\
\text { and an immortalized human gastric } \\
\text { mucosa cell line (GES-1) }\end{array}$ & $\begin{array}{l}\text { Impairing ROS generation and } \\
\text { DNA repair by the miR-200c }\end{array}$ & {$[73]$} \\
\hline
\end{tabular}


activated NF- $\kappa$ B mediates the release of IL- 6 in GC, breast cancer, glioma, and HNSCC. The IL6R/gp130/STAT3 signal pathway regulates CSC renewal and cancer metastasis which leads to radiotherapy resistance. Further investigation of treatment options addressing the pathways associated with ROS in GC may increase the sensitivity of radiotherapy in patients with GC. Since inflammatory factors play an important role in ROS-mediated TME alteration and CSCs, antiinflammatory drugs, such as NSAIDs and glucocorticoids, can be used to regulate the release of inflammatory factors and restore the aberrant TME. In addition, an optimal dosage of radiotherapy in less therapeutic frames of radiotherapy, along with other strategies to increase radiosensitivity, may significantly augment effective ROS levels for GC treatment.

\section{Additional Points}

Highlights. (i) This review focuses on recent advances in the research of radiotherapy-mediated tumor microenvironment changes in gastric cancer. (ii) There is accumulating evidence that reactive oxygen species induce the transformation of the tumor microenvironment that promotes cancer stem cells and epithelial-mesenchymal transition. (iii) This review proposes key targets for improving the radiosensitivity of gastric cancer.

\section{Conflicts of Interest}

The authors declare that there is no conflict of interest.

\section{Authors' Contributions}

All authors drafted the manuscript and approved the final version of the manuscript.

\section{Acknowledgments}

This study was supported by the National Natural Science Foundation of China (Grant no. 81673033 to Yongchang Wei).

\section{References}

[1] W. Chen, R. Zheng, P. D. Baade et al., "Cancer statistics in China, 2015," CA: A Cancer Journal for Clinicians, vol. 66, no. 2, pp. 115-132, 2016.

[2] L. A. Torre, F. Bray, R. L. Siegel, J. Ferlay, J. Lortet-Tieulent, and A. Jemal, "Global cancer statistics, 2012," CA: a Cancer Journal for Clinicians, vol. 65, no. 2, pp. 87-108, 2015.

[3] J. Ng and P. Lee, "The role of radiotherapy in localized esophageal and gastric cancer," Hematology/Oncology Clinics of North America, vol. 31, no. 3, pp. 453-468, 2017.

[4] H. H. Hartgrink, E. P. Jansen, N. C. van Grieken, and C. J. van de Velde, "Gastric cancer," The Lancet, vol. 374, no. 9688, pp. 477-490, 2009.

[5] I. Szumiel, "Ionizing radiation-induced oxidative stress, epigenetic changes and genomic instability: the pivotal role of mitochondria," International Journal of Radiation Biology, vol. 91, no. 1, pp. 1-12, 2015.
[6] J. Zhang, D. N. Tripathi, J. Jing et al., "ATM functions at the peroxisome to induce pexophagy in response to ROS," Nature Cell Biology, vol. 17, no. 10, pp. 1259-1269, 2015.

[7] T. Huang, F. Wang-Johanning, F. Zhou, H. Kallon, and Y. Wei, "MicroRNAs serve as a bridge between oxidative stress and gastric cancer (review)," International Journal of Oncology, vol. 49, no. 5, pp. 1791-1800, 2016.

[8] T. Huang, F. Zhou, F. Wang-Johanning, K. Nan, and Y. Wei, "Depression accelerates the development of gastric cancer through reactive oxygen species-activated ABL1 (review)," Oncology Reports, vol. 36, no. 5, pp. 2435-2443, 2016.

[9] H. Tu, H. Sun, Y. Lin et al., "Oxidative stress upregulates PDCD4 expression in patients with gastric cancer via miR-21," Current Pharmaceutical Design, vol. 20, no. 11, pp. 1917-1923, 2014.

[10] S. Bao, Q. Wu, R. E. McLendon et al., "Glioma stem cells promote radioresistance by preferential activation of the DNA damage response," Nature, vol. 444, no. 7120, pp. $756-$ 760, 2006.

[11] D. Triner and Y. M. Shah, "Hypoxia-inducible factors: a central link between inflammation and cancer," The Journal of Clinical Investigation, vol. 126, no. 10, pp. 3689-3698, 2016.

[12] S. Le Caër, "Water radiolysis: influence of oxide surfaces on $\mathrm{H}_{2}$ production under ionizing radiation," Water, vol. 3, no. 1 , pp. 235-253, 2011.

[13] J. Ichikawa, D. Tsuchimoto, S. Oka et al., "Oxidation of mitochondrial deoxynucleotide pools by exposure to sodium nitroprusside induces cell death," DNA Repair, vol. 7, no. 3, pp. 418-430, 2008.

[14] H. E. Barker, J. T. Paget, A. A. Khan, and K. J. Harrington, "The tumour microenvironment after radiotherapy: mechanisms of resistance and recurrence," Nature Reviews Cancer, vol. 15, no. 7, pp. 409-425, 2015.

[15] M. Diehn, R. W. Cho, N. A. Lobo et al., "Association of reactive oxygen species levels and radioresistance in cancer stem cells," Nature, vol. 458, no. 7239, pp. 780-783, 2009.

[16] C. I. Diakos, K. A. Charles, D. C. McMillan, and S. J. Clarke, "Cancer-related inflammation and treatment effectiveness," The Lancet Oncology, vol. 15, no. 11, pp. e493-e503, 2014.

[17] S. Bickelhaupt, C. Erbel, C. Timke et al., "Effects of CTGF blockade on attenuation and reversal of radiation-induced pulmonary fibrosis," Journal of the National Cancer Institute, vol. 109, no. 8, 2017.

[18] S. Rey, L. Schito, M. Koritzinsky, and B. G. Wouters, "Molecular targeting of hypoxia in radiotherapy," Advanced Drug Delivery Reviews, vol. 109, pp. 45-62, 2017.

[19] B. Thienpont, J. Steinbacher, H. Zhao et al., "Tumour hypoxia causes DNA hypermethylation by reducing TET activity," Nature, vol. 537, no. 7618, pp. 63-68, 2016.

[20] F. Klug, H. Prakash, P. E. Huber et al., "Low-dose irradiation programs macrophage differentiation to an $\mathrm{iNOS}^{+} / \mathrm{M} 1$ phenotype that orchestrates effective T cell immunotherapy," Cancer Cell, vol. 24, no. 5, pp. 589-602, 2013.

[21] F. G. Herrera, J. Bourhis, and G. Coukos, "Radiotherapy combination opportunities leveraging immunity for the next oncology practice," CA: A Cancer Journal for Clinicians, vol. 67, no. 1, pp. 65-85, 2017.

[22] T. Blankenstein, P. G. Coulie, E. Gilboa, and E. M. Jaffee, “The determinants of tumour immunogenicity," Nature Reviews. Cancer, vol. 12, no. 4, pp. 307-313, 2012. 
[23] S. Prasad, S. C. Gupta, and A. K. Tyagi, "Reactive oxygen species (ROS) and cancer: role of antioxidative nutraceuticals," Cancer Letters, vol. 387, pp. 95-105, 2017.

[24] Y. H. Hsu, C. C. Wei, D. B. Shieh, C. H. Chan, and M. S. Chang, "Anti-IL-20 monoclonal antibody alleviates inflammation in oral cancer and suppresses tumor growth," Molecular Cancer Research, vol. 10, no. 11, pp. 1430-1439, 2012.

[25] T. Monkkonen and J. Debnath, "Inflammatory signaling cascades and autophagy in cancer," Autophagy, pp. 1-9, 2017.

[26] H. Wang, L. Wang, N. L. Li et al., "Subanesthetic isoflurane reduces zymosan-induced inflammation in murine Kupffer cells by inhibiting ROS-activated p38 MAPK/NF- $\kappa \mathrm{B}$ signaling," Oxidative Medicine and Cellular Longevity, vol. 2014, Article ID 851692, 13 pages, 2014.

[27] H. Blaser, C. Dostert, T. W. Mak, and D. Brenner, "TNF and ROS crosstalk in inflammation," Trends in Cell Biology, vol. 26, no. 4, pp. 249-261, 2016.

[28] S. Petanidis, E. Kioseoglou, K. Domvri et al., "In vitro and ex vivo vanadium antitumor activity in (TGF- $\beta$ )-induced EMT. Synergistic activity with carboplatin and correlation with tumor metastasis in cancer patients," The International Journal of Biochemistry \& Cell Biology, vol. 74, pp. 121-134, 2016.

[29] A. Valavanidis, T. Vlachogianni, K. Fiotakis, and S. Loridas, "Pulmonary oxidative stress, inflammation and cancer: respirable particulate matter, fibrous dusts and ozone as major causes of lung carcinogenesis through reactive oxygen species mechanisms," International Journal of Environmental Research and Public Health, vol. 10, no. 9, pp. 3886-3907, 2013.

[30] G. Oruqaj, S. Karnati, V. Vijayan et al., "Compromised peroxisomes in idiopathic pulmonary fibrosis, a vicious cycle inducing a higher fibrotic response via TGF- $\beta$ signaling," Proceedings of the National Academy of Sciences of the United States of America, vol. 112, no. 16, pp. E2048-E2057, 2015.

[31] T. Kaur, V. Borse, S. Sheth et al., "Adenosine $A_{1}$ receptor protects against cisplatin ototoxicity by suppressing the NOX3/STAT1 inflammatory pathway in the cochlea," The Journal of Neuroscience, vol. 36, no. 14, pp. 3962-3977, 2016.

[32] Y. C. Wei, F. L. Zhou, D. L. He et al., "Oxidative stress in depressive patients with gastric adenocarcinoma," International Journal of Neuropsychopharmacology, vol. 12, no. 8, pp. 1089-1096, 2009.

[33] Y. Hayakawa, H. Ariyama, J. Stancikova et al., "Mist1 expressing gastric stem cells maintain the normal and neoplastic gastric epithelium and are supported by a perivascular stem cell niche," Cancer Cell, vol. 28, no. 6, pp. 800-814, 2015.

[34] J. C. Santos, E. Carrasco-Garcia, M. Garcia-Puga et al., "SOX9 elevation acts with canonical WNT signaling to drive gastric cancer progression," Cancer Research, vol. 76, no. 22, pp. 6735-6746, 2016.

[35] Y. Liu, M. L. Burness, R. Martin-Trevino et al., "RAD51 mediates resistance of cancer stem cells to PARP inhibition in triple-negative breast cancer," Clinical Cancer Research, vol. 23, no. 2, pp. 514-522, 2017.

[36] M. Ogrunc, R. I. Martinez-Zamudio, P. B. Sadoun et al., "USP1 regulates cellular senescence by controlling genomic integrity," Cell Reports, vol. 15, no. 7, pp. 1401-1411, 2016.

[37] S. Natarajan, F. Begum, J. Gim et al., "High mobility group A2 protects cancer cells against telomere dysfunction," Oncotarget, vol. 7, no. 11, pp. 12761-12782, 2016.
[38] I. Iacobucci, A. G. Di Rora, M. V. Falzacappa et al., "In vitro and in vivo single-agent efficacy of checkpoint kinase inhibition in acute lymphoblastic leukemia," Journal of Hematology \& Oncology, vol. 8, no. 1, p. 125, 2015.

[39] P. Zhang, Y. Wei, L. Wang et al., "ATM-mediated stabilization of ZEB1 promotes DNA damage response and radioresistance through CHK1," Nature Cell Biology, vol. 16, no. 9, pp. 864875,2014

[40] W. J. Wang, S. P. Wu, J. B. Liu et al., "MYC regulation of CHK1 and CHK2 promotes radioresistance in a stem celllike population of nasopharyngeal carcinoma cells," Cancer Research, vol. 73, no. 3, pp. 1219-1231, 2013.

[41] T. Shimura, N. Noma, T. Oikawa et al., "Activation of the $\mathrm{AKT} /$ cyclin D1/Cdk4 survival signaling pathway in radioresistant cancer stem cells," Oncogene, vol. 1, no. 6, article e12, 2012.

[42] C. Mayr, A. Wagner, M. Loeffelberger et al., "The BMI1 inhibitor PTC-209 is a potential compound to halt cellular growth in biliary tract cancer cells," Oncotarget, vol. 7, no. 1, pp. 745-758, 2016.

[43] C. Saygin, A. Wiechert, V. S. Rao et al., "CD55 regulates selfrenewal and cisplatin resistance in endometrioid tumors," The Journal of Experimental Medicine, vol. 214, no. 9, pp. 2715-2732, 2017.

[44] B. C. Lu, J. Li, W. F. Yu, G. Z. Zhang, H. M. Wang, and H. M. $\mathrm{Ma}$, "Elevated expression of $\mathrm{Nrf2}$ mediates multidrug resistance in $\mathrm{CD}_{133^{+}}$head and neck squamous cell carcinoma stem cells," Oncology Letters, vol. 12, no. 6, pp. 4333-4338, 2016.

[45] A. Sparaneo, F. P. Fabrizio, and L. A. Muscarella, "Nrf2 and notch signaling in lung cancer: near the crossroad," Oxidative Medicine and Cellular Longevity, vol. 2016, Article ID 7316492, 17 pages, 2016.

[46] Y. Mitsuishi, H. Motohashi, and M. Yamamoto, "The Keap1-Nrf2 system in cancers: stress response and anabolic metabolism," Frontiers in Oncology, vol. 2, p. 200, 2012.

[47] R. Wang, J. Wei, S. Zhang et al., "Peroxiredoxin 2 is essential for maintaining cancer stem cell-like phenotype through activation of Hedgehog signaling pathway in colon cancer," Oncotarget, vol. 7, no. 52, pp. 86816-86828, 2016.

[48] A. Perkins, K. J. Nelson, D. Parsonage, L. B. Poole, and P. A. Karplus, "Peroxiredoxins: guardians against oxidative stress and modulators of peroxide signaling," Trends in Biochemical Sciences, vol. 40, no. 8, pp. 435-445, 2015.

[49] V. Kumar and D. I. Gabrilovich, "Hypoxia-inducible factors in regulation of immune responses in tumour microenvironment," Immunology, vol. 143, no. 4, pp. 512-519, 2014.

[50] J. Bensimon, D. Biard, V. Paget et al., "Forced extinction of CD24 stem-like breast cancer marker alone promotes radiation resistance through the control of oxidative stress," Molecular Carcinogenesis, vol. 55, no. 3, pp. 245-254, 2016.

[51] I. Skvortsova, P. Debbage, V. Kumar, and S. Skvortsov, "Radiation resistance: cancer stem cells (CSCs) and their enigmatic pro-survival signaling," Seminars in Cancer Biology, vol. 35, pp. 39-44, 2015.

[52] M. Krause, A. Dubrovska, A. Linge, and M. Baumann, "Cancer stem cells: radioresistance, prediction of radiotherapy outcome and specific targets for combined treatments," Advanced Drug Delivery Reviews, vol. 109, pp. 63-73, 2016.

[53] M. E. Prince, R. Sivanandan, A. Kaczorowski et al., "Identification of a subpopulation of cells with cancer stem cell properties in head and neck squamous cell carcinoma," Proceedings of the 
National Academy of Sciences of the United States of America, vol. 104, no. 3, pp. 973-978, 2007.

[54] M. Zoller, "CD44: can a cancer-initiating cell profit from an abundantly expressed molecule?," Nature Reviews Cancer, vol. 11, no. 4, pp. 254-267, 2011.

[55] H. Kinugasa, K. A. Whelan, K. Tanaka et al., "Mitochondrial SOD2 regulates epithelial-mesenchymal transition and cell populations defined by differential CD44 expression," Oncogene, vol. 34, no. 41, pp. 5229-5239, 2015.

[56] V. J. Findlay, C. Wang, D. K. Watson, and E. R. Camp, "Epithelial-to-mesenchymal transition and the cancer stem cell phenotype: insights from cancer biology with therapeutic implications for colorectal cancer," Cancer Gene Therapy, vol. 21, no. 5, pp. 181-187, 2014.

[57] P. Csermely, J. Hodsagi, T. Korcsmaros et al., "Cancer stem cells display extremely large evolvability: alternating plastic and rigid networks as a potential mechanism: network models, novel therapeutic target strategies, and the contributions of hypoxia, inflammation and cellular senescence," Seminars in Cancer Biology, vol. 30, pp. 42-51, 2015.

[58] P. H. Nguyen, J. Giraud, L. Chambonnier et al., "Characterization of biomarkers of tumorigenic and chemoresistant cancer stem cells in human gastric carcinoma," Clinical Cancer Research, vol. 23, no. 6, pp. 1586-1597, 2016.

[59] S. Nakajima and M. Kitamura, "Bidirectional regulation of NF- $\kappa$ B by reactive oxygen species: a role of unfolded protein response," Free Radical Biology and Medicine, vol. 65, pp. 162-174, 2013.

[60] D. Capece, D. Verzella, A. Tessitore, E. Alesse, C. Capalbo, and F. Zazzeroni, "Cancer secretome and inflammation: the bright and the dark sides of NF- $\kappa \mathrm{B}$," Seminars in Cell \& Developmental Biology, 2017.

[61] R. Bharti, G. Dey, and M. Mandal, "Cancer development, chemoresistance, epithelial to mesenchymal transition and stem cells: a snapshot of IL-6 mediated involvement," Cancer Letters, vol. 375, no. 1, pp. 51-61, 2016.

[62] K. Middleton, J. Jones, Z. Lwin, and J. I. Coward, "Interleukin-6: an angiogenic target in solid tumours," Critical Reviews in Oncology/Hematology, vol. 89, no. 1, pp. 129-139, 2014.

[63] S. Cohen, I. Bruchim, D. Graiver et al., "Platinum-resistance in ovarian cancer cells is mediated by IL- 6 secretion via the increased expression of its target cIAP-2," Journal of Molecular Medicine, vol. 91, no. 3, pp. 357-368, 2013.

[64] K. Storch, E. Dickreuter, A. Artati, J. Adamski, and N. Cordes, "BEMER electromagnetic field therapy reduces cancer cell radioresistance by enhanced ROS formation and induced DNA damage," PLoS One, vol. 11, no. 12, article e0167931, 2016.

[65] B. Yu, T. Liu, Y. Du, Z. Luo, W. Zheng, and T. Chen, "X-rayresponsive selenium nanoparticles for enhanced cancer chemo-radiotherapy," Colloids and Surfaces B: Biointerfaces, vol. 139, pp. 180-189, 2016.

[66] G. Dong, Q. Chen, F. Jiang et al., "Diisopropylamine dichloroacetate enhances radiosensitization in esophageal squamous cell carcinoma by increasing mitochondria-derived reactive oxygen species levels," Oncotarget, vol. 7, no. 42, pp. 6817068178, 2016.
[67] S. Karthik, R. Sankar, K. Varunkumar, C. Anusha, and V. Ravikumar, "Blocking NF- $\kappa$ B sensitizes non-small cell lung cancer cells to histone deacetylase inhibitor induced extrinsic apoptosis through generation of reactive oxygen species," Biomedicine \& Pharmacotherapy, vol. 69, pp. 337-344, 2015.

[68] P. Perez-Galan, G. Roue, N. Villamor, E. Montserrat, E. Campo, and D. Colomer, "The proteasome inhibitor bortezomib induces apoptosis in mantle-cell lymphoma through generation of ROS and Noxa activation independent of p53 status," Blood, vol. 107, no. 1, pp. 257-264, 2006.

[69] M. W. Sung, D. Y. Lee, S. W. Park et al., "Celecoxib enhances the inhibitory effect of 5-FU on human squamous cell carcinoma proliferation by ROS production," The Laryngoscope, vol. 127, no. 4, pp. E117-E123, 2017.

[70] P. Sonkusre and S. S. Cameotra, "Biogenic selenium nanoparticles induce ROS-mediated necroptosis in PC-3 cancer cells through TNF activation," Journal of Nanobiotechnology, vol. 15, no. 1, p. 43, 2017.

[71] M. Pajic, D. Froio, S. Daly et al., “miR-139-5p modulates radiotherapy resistance in breast cancer by repressing multiple gene networks of DNA repair and ROS defense," Cancer Research, vol. 78, no. 2, pp. 501-515, 2018.

[72] Y. Yang, M. Jiang, J. Hu et al., "Enhancement of radiation effects by ursolic acid in BGC-823 human adenocarcinoma gastric cancer cell line," PLoS One, vol. 10, no. 7, article e0133169, 2015.

[73] F. B. Cui, Q. Liu, R. T. Li et al., "Enhancement of radiotherapy efficacy by miR-200c-loaded gelatinase-stimuli PEG-Pep-PCL nanoparticles in gastric cancer cells," International Journal of Nanomedicine, vol. 9, pp. 2345-2358, 2014. 


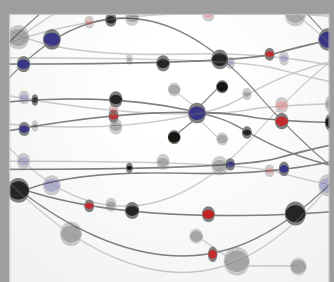

The Scientific World Journal
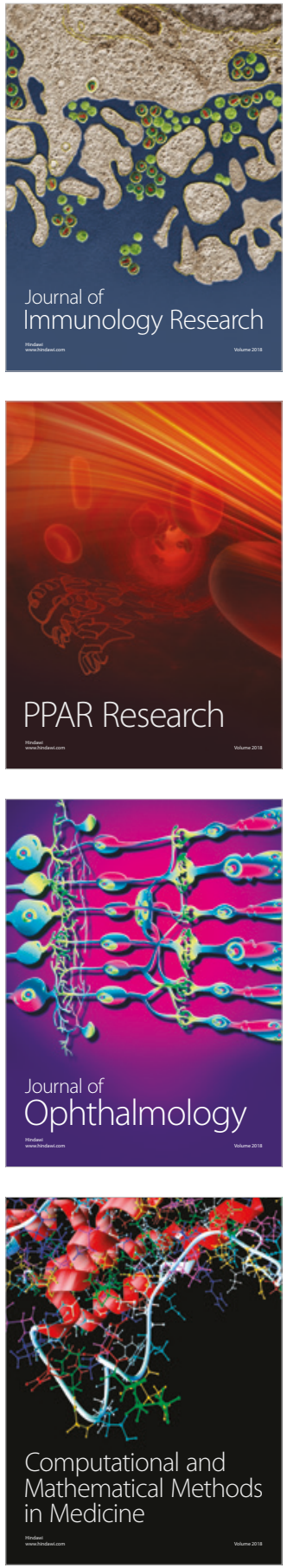

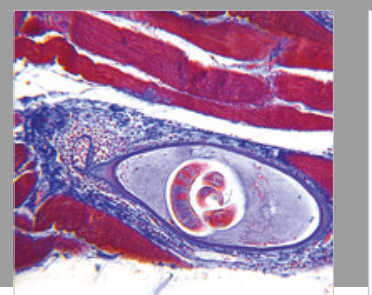

Gastroenterology Research and Practice

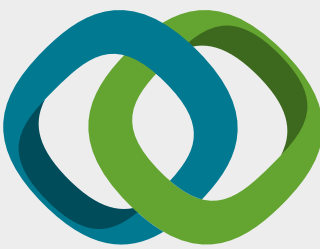

\section{Hindawi}

Submit your manuscripts at

www.hindawi.com
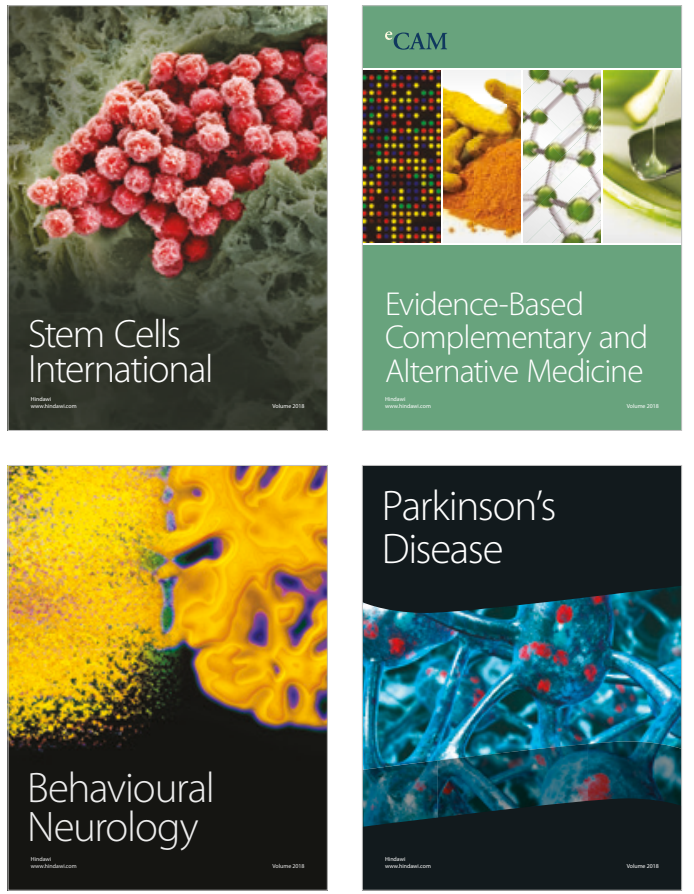

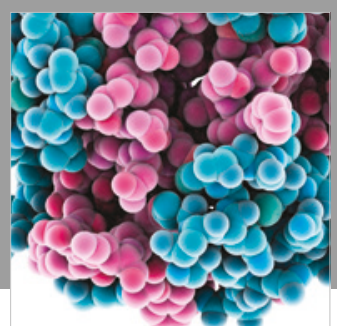

ournal of

Diabetes Research

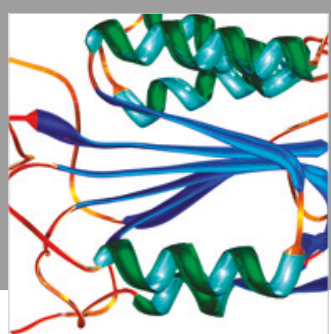

Disease Markers
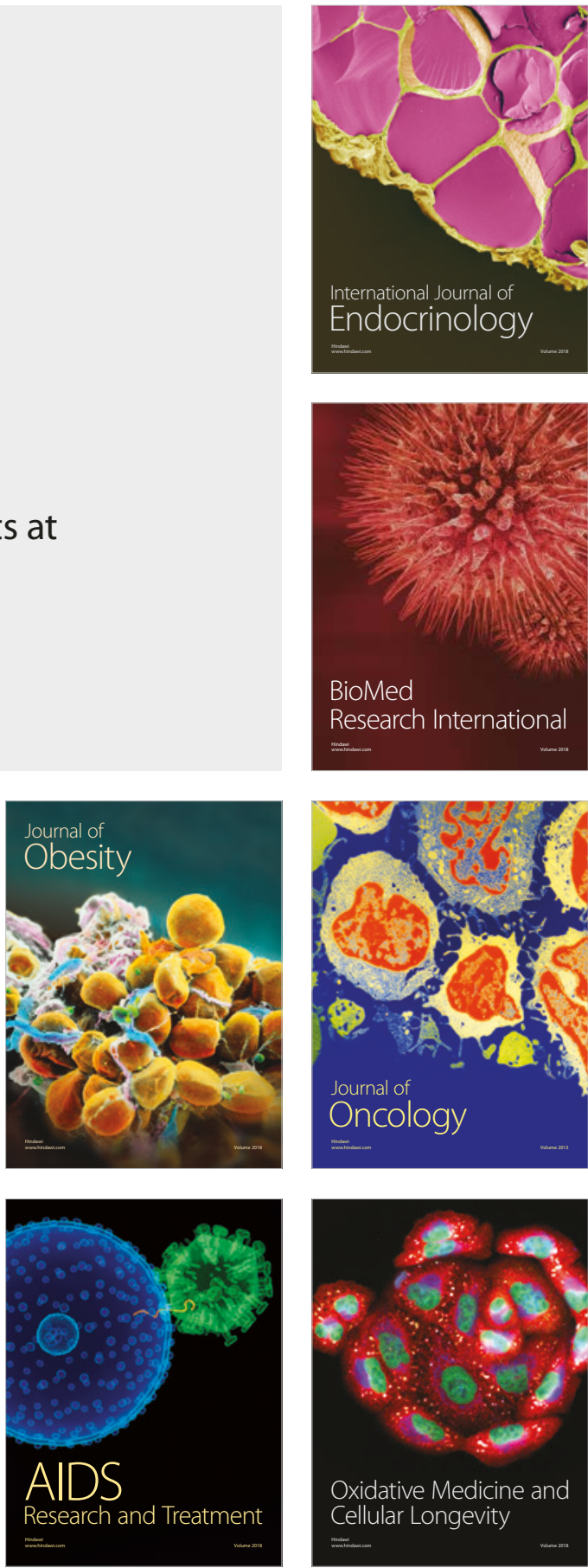